\title{
FINANCIAL STATEMENT QUALITY AND INVESTMENT EFFICIENCY
}

\author{
Indah Umiyatia ${ }^{a}$, Riyanto ${ }^{b}$ \\ aSekolah Tinggi IImu Ekonomi Sutaatmadja \\ Email : indah@stiesa.ac.id \\ bUniversitas Indonesia
}

\begin{tabular}{|c|c|}
\hline INFO ARTIKEL & ABSTRAK/ABSTRACK \\
\hline $\begin{array}{l}\text { Histori Artikel : } \\
\text { Tgl. Masuk : } 06 \text { MAret } 2019 \\
\text { Tgl. Diterima } 18 \text { Maret } 2019 \\
\text { Tersedia Online: } 29 \text { Maret } \\
2019\end{array}$ & $\begin{array}{l}\text { This study aims to analyze the relationship between } \\
\text { financial statements quality with reduced over-investment } \\
\text { and under-investment. The study was conducted on } \\
\text { companies listed on the Indonesia Stock Exchange in 2008- }\end{array}$ \\
\hline $\begin{array}{l}\text { Keywords: } \\
\text { financial statements quality, } \\
\text { over-investment, under- } \\
\text { investment }\end{array}$ & $\begin{array}{l}2015 \text { totaling } 1,525 \text { years. The analysis was done using an } \\
\text { estimation of multinomial logistic regression. The results of } \\
\text { the data analysis show that financial statements quality } \\
\text { does not have an influence on the reduced opportunities for } \\
\text { over-investment or under investment. }\end{array}$ \\
\hline
\end{tabular}

\section{PENDAHULUAN}

Beberapa penelitian terdahulu menemukan bahwa laporan keuangan dengan kualitas yang baik akan meningkatkan efisiensi investasi (Bushman dan Smith, 2001; Healy dan Palepu, 2001). Konsisten dengan hal tersebut, Biddle dan Hilary (2006) menemukan bahwa perusahaan dengan kualitas laporan keuangan yang baik akan menghasilkan investasi yang lebih efisien yang diproksikan dengan investment-cash flow sensitivity yang lebih rendah. Namun, investment-cash flow sensitivity bias menggambarkan baik keterbatasan pembiayaan maupun kelebihan kas (Kaplan, 1997; Fazzari et al., 2000). Pertanyaan selanjutnya dari hasil penelitian tersebut adalah apakah kualitas laporan keuangan yang baik berhubungan dengan berkurangnya over-investment atau berkurangnya under-investment. Penelitian ini bertujuan untuk melihat hubungan kualitas laporan keuangan dengan berkurangnya over-investment dan under-investment.

\section{KERANGKA TEORITIS DAN PENGEMBANGAN HIPOTESIS}

Asimetri informasi antara perusahaan dan pemasok modal bisa mengurangi efisiensi investasi. Hal ini terjadi karena timbulnya permasalahan moral hazard dan adverse selection bisa mendorong terjadinya over-investment dan under-investment.

Penelitian sebelumnya mengatakan bahwa laporan keuangan dengan kualitas yang baik akan mendorong terjadinya efisiensi investasi dengan mengurangi asimetri informasi yang bisa menimbulkan permasalahan ekonomi seperti moral hazard dan adverse selection (Leuz dan Verrechia, 2000; Bushman dan Smith, 2001, Verrechia, 2001). Hal ini terjadi karena laporan informasi yang terkandung dalam laporan keuangan digunakan oleh pemegang saham untuk melakukan pengawasan terhadap manajer (Bushman 
and Smith, 2001; Lambert, 2001) dan merupakan sumber utama bagi investor untuk mengetahui informasi perusahaan yang spesifik (Bushman dan Indjejikian, 1993; Holmstrom dan Tirole, 1993, Kanodia dan Lee, 1998). Jika laporan keuangan dengan kualitas yang baik meningkatkan kemampuan pemegang saham untuk mengawasi aktivitas investasi manajer, maka hal tersebut berhubungan dengan efisiensi investasi melalui berkurangnya kemungkinan terjadinya moral hazard.

Pada kondisi lain, keberadaan asimetri informasi antara perusahaan dan investor akan mendorong para pemasok modal berkesimpulan bahwa menanamkan modal pada perusahaan tersebut keputusan yang salah dan akan mengurangi harga sahamnya (Myers and Majluf, 1984). Kualitas laporan keuangan akan mengurangi permasalahan ini, Chang et al. (2009) menunjukkan secara empiris bahwa perusahaan yang mempunyai kualitas laporan keuangan yang lebih baik akan lebih fleksibel dalam menawarkan penanaman modalnya. Biddle et al. (2009) mengatakan jika kualitas laporan keuangan mengurangi biaya adverse selection, maka kondisi tersebut akan berhubungan dengan efisiensi investasi melalui berkurangnya biaya pembiayaan eksternal dan berkurangnya kecenderungan perusahaan menerima kelebihan dana karena kesalahan menilai perusahaan (mispricing) yang bersifat sementara.

Dari uraian diatas, diduga bahwa kualitas laporan keuangan yang baik akan berhubungan negatif dengan efisiensi investasi baik over-investment maupun under-investment. Sehingga ditetapkan hipotesis sebagai berikut:
$\mathrm{H} 1 \mathrm{a}$ : Kualitas laporan keuangan mengurangi peluang terjadinya overinvestment.

$\mathrm{H} 1 \mathrm{~b}$ : Kualitas laporan keuangan mengurangi peluang terjadinya underinvestment.

\section{METODOLOGI PENELITIAN}

Pengujian dalam penelitian ini didasarkan pada metode yang digunakan oleh Biddle, et al. (2009) dan Garcia Lara et al. (2016), yang bisa memperlihatkan analisis bagaimana pilihan metode akuntansi bisa mengurangi terjadinya over-investment dan under-investment. Model yang digunakan adalah sebagai berikut :

$$
\begin{aligned}
& \text { prob_inv }_{t+1}=\alpha_{1}+\beta_{1} F R Q_{i, t}+ \\
& \text { Control }_{j, i, t}+\varepsilon_{1 i, t+1}
\end{aligned}
$$

prob_inv $_{t+1}$ adalah kondisi overinvestment atau under-investment pada sebuah perusahaan di tahun tertentu yang dihitung menggunakan persamaan sebagai berikut :

$$
\begin{aligned}
& \text { Investment }_{i, t}=\alpha_{2}+ \\
& \theta_{1} \text { Salesgrowth }_{i, t-1}+\varepsilon_{2 i, t}
\end{aligned}
$$

(2)

Investment, diukur dengan jumlah dari capital expenditure, research and development expenditure, dan acquitision expenditure dikurangi dengan penerimaan kas dari penjualan property, plant and equipment (PPE), dikali dengan 100, kemudian dibagi dengan total asset (Biddle et al., 2009; Garcia Lara et al., 2016).

$$
\begin{gathered}
\text { Investment }= \\
\frac{[(\text { capex }+R \& D+\text { acquire })-(P P E \text { sales })]}{\text { total assets }} \times 100
\end{gathered}
$$

Salesgrowth adalah perubahan penjualan tahun $t$ dibandingkan dengan $t-$ 1 yang dihitung sebagai berikut : 


$$
\text { Salesgrowth }=100 \times \frac{\Delta \text { Sales }_{i, t}}{\text { Sales }_{i, t-1}}
$$

$\begin{array}{ccc}\text { Model (2) } & \text { kemudian diestimasi } \\ \text { untuk setiap } & \text { kelompok industry }\end{array}$ (berdasarkan digit JASICA). Untuk mengetahui kecenderungan overinvestment dan under-investment, nilai residual dari model (2) diurutkan kemudian dikelompokkan ke dalam kuartil. Kelompok perusahaan pada nilai kuartil tertinggi (residual paling positif) menunjukkan kondisi over-investment. Kelompok perusahaan dengan nilai kuartil terendah (residual paling negatif) menunjukkan kondisi under-investment. Kelompok perusahaan dengan dua nilai kuartil tengah diklasifikasikan sebagai kelompok benchmark, memperlihatkan kondisi investasi optimal.

Penelitian ini menggunakan model Stubben (2010) untuk mengukur kualitas akrual sebagai proksi dari kualitas laporan keuangan, sbb:

$$
\Delta A R_{i t}=\alpha_{3}+\partial_{1} \Delta R_{i t}+\varepsilon_{3 i t}
$$

AR adalah piutang perusahaan dan $R$ adalah revenue perusahaan. $F R Q$ merupakan nilai absolut residual pada setiap perusahaan dari model (3) kemudian dikalikan dengan negatif satu.

Variabel kontrol yang dimasukan ke dalam model (1) adalah faktor-faktor yang diduga mempengaruhi kualitas akrual dan perilaku investasi. Variabel tersebut adalah volatilitas penjualan dan cash flow terkait dengan kualitas akrual (Liu dan Wysocki, 2007) serta variabel volatilitas investasi (Biddle et al., 2009; Garcia Lara et al., 2009).

\section{Variabel Kontrol}

\section{Nama Pengukuran Variabel}

\begin{tabular}{|l|l|}
\hline$\delta($ CFO) & $\begin{array}{l}\text { Standard deviasi dari arus } \\
\text { kas dari aktifitas operasional } \\
\text { dibagi dengan rata-rata total } \\
\text { asset dari tahun t-5 sampai } \\
\text { dengan t-1. }\end{array}$ \\
\hline$\delta$ (Sales) & $\begin{array}{l}\text { Standard deviasi dari } \\
\text { penjualan dibagi dengan rata- } \\
\text { rata total asset dari tahun t-5 } \\
\text { sampai dengan t-1. }\end{array}$ \\
\hline$\delta$ (Invest) & $\begin{array}{l}\text { Standard deviasi dari } \\
\text { investasi (investment, capital } \\
\text { expenditure dan non-capital } \\
\text { expenditure) dari tahun t-5 } \\
\text { sampai dengan t-1. }\end{array}$ \\
\hline
\end{tabular}

Untuk membuktikan hipotesis penelitian model (1) diestimasi menggunakan multinomial logit model yang memprediksi peluang sebuah perusahaan akan berada pada kuartil tertinggi (terendah) dibandingkan dengan kuartil tengah. $\mathrm{H} 1 \mathrm{a}$ dan $\mathrm{H} 1 \mathrm{~b}$ menduga bahwa perusahaan dengan kualitas laporan keuangan yang lebih tinggi akan memiliki peluang yang lebih rendah (negatif) untuk berada pada kuartil tertinggi (terendah).

Penelitian ini menggunakan perusahaan yang terdaftar di Bursa Efek Indonesia (BEI) kecuali perusahaan yang termasuk ke dalam kelompok industry keuangan. Perusahaan yang termasuk ke dalam industry keuangan diduga memiliki sifat yang berbeda sehingga tidak dimasukan sebagai sampel penelitian.

Periode penelitian yang dimasukkan ke dalam model 1 adalah tahun 2011 sampai dengan 2015. Namun, untuk menghitung data penelitian diperlukan data dari tahun 2008. Sehingga diperlukan perusahaan yang terdaftar di BEI dari tahun 2008. Berdasarkan persyaratan tersebut dan perusahaan mempunyai data yang diperlukan penelitian secara lengkap, maka diperoleh 
305 perusahaan sampel dengan periode penelitian 5 tahun (2011 s.d. 2015). Sampel akhir penelitian adalah 1.525 firmyears.

Pengelompokkan perusahaan didasarkan pada indeks JASICA yaitu angka 1 sampai dengan 9 (kecuali angka 8 untuk industry keuangan) untuk digit pertama. Data penelitian diperoleh dari datastream Pusat Data Ekonomi dan Bisnis (PDEB) Fakultas Ekonomi Universitas Indonesia (FE-UI) dan website resmi BEI yaitu www.idx.co.id.

\section{HASIL DAN PEMBAHASAN}

Statistik deskriptif untuk variable penelitian yang bersifat rasio adalah sebagai berikut (table 1):

\section{Table 1}

\section{Statistik Desktiptif variable independen}

\begin{tabular}{|c|c|c|c|c|c|}
\hline & $\begin{array}{l}\text { Observ } \\
\text { si }\end{array}$ & Mean & $\begin{array}{l}\text { Std. } \\
\text { Devia } \\
\text { si }\end{array}$ & Min & Max \\
\hline$\overline{F R Q}$ & 1.525 & 1,677 & $\begin{array}{l}18,21 \\
2\end{array}$ & $\begin{array}{l}- \\
591,2 \\
4\end{array}$ & $\begin{array}{l}- \\
00,00 \\
2\end{array}$ \\
\hline $\begin{array}{l}\delta(\text { Inves } \\
\text { t) }\end{array}$ & 1.525 & $\begin{array}{l}0,037 \\
0\end{array}$ & 0,050 & 0,000 & $\begin{array}{l}0,37 \\
8\end{array}$ \\
\hline $\begin{array}{l}\delta(\text { Sale } \\
\text { s) }\end{array}$ & 1.525 & 0,166 & 0,345 & 0,001 & $\begin{array}{l}7,72 \\
6\end{array}$ \\
\hline $\bar{\delta}(\mathrm{CFO})$ & 1.525 & 0,060 & 0,071 & 0,001 & $\begin{array}{l}0,88 \\
2\end{array}$ \\
\hline
\end{tabular}

Sedangkan untuk variable yang bersifat nominal, yaitu perusahaan dalam kondisi under-investment, optimalinvestment dan over-investment adalah sebagai berikut (table 2):

\section{Table 2}

\section{Statistik Desktiptif Dependen} (prob_inv)

\section{Nilai Frekuensi Persentase}

\begin{tabular}{|l|l|l|l|}
\hline $\begin{array}{l}\text { Under- } \\
\text { investment }\end{array}$ & 1 & 379 & $25 \%$ \\
\hline $\begin{array}{l}\text { Optimal- } \\
\text { investment }\end{array}$ & 2 & 750 & $49 \%$ \\
\hline $\begin{array}{l}\text { Over- } \\
\text { investment }\end{array}$ & 3 & 396 & $26 \%$ \\
\hline
\end{tabular}

Korelasi Pearson antar variable dapat dilihat di table 3. Pada table 3 terlihat bahwa kualitas laporan keuangan berkorelasi negatif dengan kondisi perusahaan terkait dengan kondisi underinvestment, optimal-investment dan overinvestment. Dari korelasi tersebut dapat disimpulkan bahwa semakin baik kualitas laporan keuangan maka kemungkinan perusahaan yang berada suatu kelompok investasi tertentu akan beralih kepada kelompok investasi di bawahnya. Misalnya ketika perusahaan berada pada kondisi over-investment, jika kualitas laporan keuangannya semakin baik akan mempunyai kemungkinan untuk menuju kearah optimal-investment.

Table 3

\section{Korelasi Pearson}

\begin{tabular}{|c|c|c|c|c|c|}
\hline & $\left|\begin{array}{l}\text { Prob_i } \\
\text { nv }\end{array}\right|$ & FRQ & $\begin{array}{l}\delta(\text { Inve } \\
\text { st) }\end{array}$ & $\begin{array}{l}\delta \text { (Sale } \\
\text { s) }\end{array}$ & $\begin{array}{l}\delta(C F \\
0) \\
\end{array}$ \\
\hline $\begin{array}{l}\text { Prob_i } \\
\text { nv }\end{array}$ & 1,0000 & & & & \\
\hline FRQ & $-0,0433$ & $\begin{array}{l}1,00 \\
00\end{array}$ & & & \\
\hline $\begin{array}{l}\delta(\text { Inve } \\
\text { st) }\end{array}$ & $-0,0383$ & $\begin{array}{l}- \\
0,00 \\
76\end{array}$ & 1,0000 & & \\
\hline $\begin{array}{l}\delta \text { (Sale } \\
\text { s) }\end{array}$ & $-0,0084$ & \begin{tabular}{|l|}
0,13 \\
97
\end{tabular} & 0,1321 & 1,0000 & \\
\hline$\delta$ (CFO) & $-0,0294$ & $\begin{array}{l}0,00 \\
44\end{array}$ & 0,2747 & 0,2765 & $\begin{array}{l}1,000 \\
0\end{array}$ \\
\hline
\end{tabular}


Hasil multinomial logistik untuk perusahaan under-investment dan overinvestment ditunjukkan pada tabel 4 . Optimal-investment tidak ditampilkan karena merupakan kelompok benchmark. Uji kecocokan model dilihat dari probabilitas chi-square sebesar 0,3638. Nilai ini menunjukkan model tersebut kurang fit untuk bisa digunakan sebagai prediksi.

Koefisien negatif pada underinvestment menunjukkan bahwa semakin baik kualitas keuangan, maka peluang terjadinya under-investment lebih dibandingkan dengan optimal-investment. Koefisien negatif pada over-investment menunjukkan bahwa semakin baik kualitas keuangan, maka peluang terjadinya overinvestment lebih besar dibandingkan dengan optimal-investment. Namun kedua koefisien tidak signifikan, sehingga hipotesis penelitian tidak terbukti.

Table 4

\section{Hasil Regresi Logistic}

\begin{tabular}{|l|l|l|}
\hline \multicolumn{2}{|l|}{$\begin{array}{l}\text { Under- } \\
\text { investment }\end{array}$} & $\begin{array}{l}\text { Over- } \\
\text { investment }\end{array}$ \\
\hline \multicolumn{2}{|l|}{ Koefisien } \\
\hline Const & $-0,7852$ & $-0,6363$ \\
\hline FRQ & 0,0042 & $-0,0049$ \\
\hline$\delta$ (Invest) & 1,0751 & $-0,7070$ \\
\hline$\delta$ (Sales) & 0,2774 & 0,2135 \\
\hline$\delta($ CFO) & 0,3267 & $-0,3477$ \\
\hline Chi-square & 8,75 \\
\hline Prob & 0,3638 \\
\hline Pseudo $R^{2}$ & 0,0037 \\
\hline
\end{tabular}

Untuk melihat pengaruh kualitas laporan keuangan terhadap peluang terjadinya under-investment, optimalinvestment dan over-investment, maka bisa dilihat dari nilai average marginal effect pada tabel 5. Average marginal effect untuk $\mathrm{FRQ}$ pada under-investment adalah 0,0011. Hal ini menunjukkan untuk setiap kenaikan $1 \%$ kualitas laporan keuangan akan menaikkan peluang terjadinya under-investment sebesar $0,11 \%$. Namun nilai tersebut tidak signifikan sehingga tidak bisa digunakan sebagai dasar untuk memprediksi.

Average marginal effect untuk $F R Q$ pada optimal-investment adalah 0,0001. Hal ini menunjukkan untuk setiap kenaikan $1 \%$ kualitas laporan keuangan akan menaikkan peluang terjadinya optimalinvestment sebesar $0,11 \%$. Namun nilai tersebut tidak signifikan sehingga tidak bisa digunakan sebagai dasar untuk memprediksi.

Average marginal effect untuk FRQ pada optimal-investment adalah -0,0012. Hal ini menunjukkan untuk setiap kenaikan $1 \%$ kualitas laporan keuangan akan menurunkan peluang terjadinya overinvestment sebesar $0,12 \%$. Namun nilai tersebut tidak signifikan sehingga tidak bisa digunakan sebagai dasar untuk memprediksi.

Tabel 5

Average Marginal Effect

\begin{tabular}{|l|c|c|c|}
\hline & $\begin{array}{c}\text { Under- } \\
\text { investme } \\
\text { nt } \\
\mathbf{( 1 )}\end{array}$ & $\begin{array}{c}\text { Optimal- } \\
\text { investme } \\
\text { nt } \\
\mathbf{( 2 )}\end{array}$ & $\begin{array}{c}\text { Over- } \\
\text { investme } \\
\text { nt } \\
\mathbf{( 3 )}\end{array}$ \\
\hline $\mathrm{FRQ}$ & 0,0011 & 0,0001 & $-0,0012$ \\
\hline$\delta$ (Invest & 0,2455 & $-0,0411$ & $-0,0204$ \\
\hline$\delta$ (Sales & 0,0379 & $-0,0610$ & 0,0231 \\
\hline$\delta($ CFO) & 0,0831 & $-0,0044$ & $-0,0876$ \\
\hline
\end{tabular}

\section{Kesimpulan}

Hasil analisis data menunjukkan bahwa kualitas laporan keuangan tidak mempunyai pengaruh terhadap 
berkurangnya peluang terjadinya overinvestment maupun under investment. Hal ini diduga karena pasar modal di Indonesia yang kepemilikan perusahaan terbuka belum tersebar luas, masih didominasi oleh pemegang saham mayoritas. Hal ini mengakibatkan mekanisme investasi masih dipegang oleh pemerang saham mayoritas yang mempunyai kendali atas perusahaan, sehingga kualitas laporan keuangan yang menjadi alat komunikasi antara investor dan perusahaan menjadi tidak berperan.

\section{REFERENCES}

Abel, A., 1983. Optimal-investment under uncertainty. American Economic Review, 73, 228-233.

Baker, M., Stein, J., Wurgler, J., 2003. When does the market matter? Stock prices and the investment of equity-dependent firms. Quarterly Journal of Economics,118, 9691005.

Bernard, V., and D. Skinner. 1996. What motivates managers' choice of discretionary accruals? Journal of Accounting and Economics 22: 313-325.

Biddle, G., Hilary, G., 2006. Accounting quality and firm-level capital investment. The Accounting Review, 81, 963-982

Biddle, G.C., Hilary, G., Verdi, R.S., 2009. How does financial reporting quality improve investment efficiency? Journal of Accounting and Economincs, 48, 112-131

Biswas, D. 2004 Economics of information in the web economy: towards a new theory? Journal of Bussiness Research, 57(7), 724-33

Blanchard, O., Lopez-de-Silanez, F., Shleifer, A., 1994. What do firms do with cash windfalls? Journal of Financial Economics 36, 337-360.

Bushman, R., Indjejikian, R., 1993. Shareholder demand for "distorted" accounting disclosures. The Accounting Review, 68, 765782.

Bushman, R., Smith, A., 2001. Financial accounting information and corporate governance. Journal of Accounting and Economics, 31, 237-333.

Chang, X., Dasgupta, S., Hilary, G., 2009. The effect of auditor quality on financing decisions. The Accounting Review, 84, 10851117.

Copeland TE, Galai D. 1983. Information effects on the bid-ask spread. Journal of Finance, 38(5):14571469.

Czepiel, S. A. ---. Maximum Likelihood Estimation of Logistic Regression Models, Theory dan Implementation.

Dechow, P., Dichev, I., 2002. The quality of accruals and earnings: the role of accrual estimation errors. The Accounting Review, 77, 35-59.

Easley D, Hvidkjaer S, O'Hara M. 2002. Is information risk a determinant of asset returns? Journal of Finance, 57(5), 2185-2221

Fazzari, S., Hubbard, G., Petersen, B., 2000. Investment-cash flow sensitivities are not useful: a comment on Kaplan and Zingales. Quarterly Journal of Economics, 115, 695-705.

Garcia Lara, J. M., Garcia Osma, B., Penalva, F., 2016. Accounting conservatism and firm investment 
efficiency. Journal of Accounting and Economics, 61, 221-238

Glosten LR, Harris LE. 1988. Estimating the components of the bid-ask spread. Journal of Financial Economics, 21(1),123-42.

Grewala D, lyerb GR, Krishnanc R, Sharmad A. 2003, The Internet and the price-value-loyalty chain. Journal of Bussiness Research, 56(5),391-398.

Gujarati, D. N. \& Porter, D. C. 2009. Basic Econometrics $5^{\text {th }}$ Edition, MC Graw-Hill.

Hayashi, F., 1982. Tobin's marginal q and average q: a neoclassical interpretation. Econometrica, 50, 213-224.

Healy, P., Palepu, K., 2001. Information asymmetry, corporate disclosure, and the capital markets: a review of the empirical disclosure literature. Journal of Accounting and Economics, 31, 405-440.

Holmstrom, B., Tirole, J., 1993. Market liquidity and performance monitoring. Journal of Political Economy, 101, 678-709.

Indonesian Stock Exchange, Fact Book IDX 2016, Jakarta, 2016

Jensen, M., 1986. Agency costs of free cash flow, corporate finance, and takeovers. American Economic Review, 76, 323-329.

Jensen, M., Meckling,W., 1976. Theory of the firm: managerial behavior, agency costs and ownership structure. Journal of Financial Economics, 3, 305-360.

Kanodia, C., Lee, D., 1998. Investment and disclosure: the disciplinary role of periodic performance reports.
Journal of Accounting Research, 36, 33-55.

Kaplan, S., Zingales, L., 1997. Do financing constraints explain why investment is correlated with cashflows? Quarterly Journal of Economics, 112, 169-215.

Kulkarni SP. 2000. The influence of information technology on information asymmetry in product markets. Journal of Bussiness Economics Studies, 6(1), 55-72.

Lambert, R., 2001. Contracting theory and accounting. Journal of Accounting and Economics, 32, 3-87.

Leuz, C., Verrecchia, R., 2000. The economic consequences of increased disclosure. Journal of Accounting Research, 38, 91-124.

Liu, M., Wysocki, P., 2007. Cross-sectional determinants of information quality proxies and cost of capital measures. Working Paper, MIT.

McNichols, M. 2002. Discussion of the quality of accruals and earnings: The role of accrual estimation errors. The Accounting Review, 77 (Supplement): 61-69.

McNichols, M., and P. Wilson. 1988. Evidence of earnings management from the provision for bad debts. Journal of Accounting Research, 26 (Supplement): 1-31

Myers, S., Majluf, N., 1984. Corporate financing and investment decisions when firms have information that investors do not have. Journal of Financial Economics, 13, 187-221.

Stubben, S.R. Discretionary Revenues as Measure of Earnings Management. The Accounting Review, 85(2), 695-717. 
Verrecchia, R., 2001. Essays on disclosure. Journal of Accounting and Economics, 32, 91-180.

Yoon, H., Zo, H., Ciganek, A.P. 2011. Does XBRL adoption reduce information asymmetry? Journal of Bussiness Research, 64, 157-163.
Yoshikawa, H., 1980. On the "q" theory of investment. American Economic Review, 70, 739-743 